\title{
Different progestagen treatment duration on estrous synchronization during the natural breeding season in non-lactating Anatolian black goats
}

\author{
I. Dogan ${ }^{1,3}$, Z. Nur ${ }^{1}$, S. Dogan ${ }^{2}$ \\ ${ }^{1}$ Uludag University, Veterinary Faculty, Department of Reproduction and Artificial Insemination, \\ Gorukle/Bursa, Turkey. \\ ${ }^{2}$ Uludag University, Institute of Health Science, Gorukle/Bursa, Turkey.
}

\begin{abstract}
The objective of this study was to evaluate the duration of four progestagen treatments on estrous synchronization and pregnancy rate in non-lactating Anatolian black goats during the natural breeding season. All does were divided into four groups according to progestagen treatment duration using intravaginal sponges (60 mg MAP): group 1, 13 days $(\mathrm{n}=23)$, group 2,11 days $(\mathrm{n}=25)$, group 3,9 days $(\mathrm{n}=25)$ and group 4,6 days $(\mathrm{n}=25)$. In addition, $24 \mathrm{~h}$ before sponges removal, each doe was injected with $0.075 \mathrm{mg}$ of cloprostenol (PGF2 $\alpha$ ) and $500 \mathrm{IU}$ eCG. The goats within the same group were naturally mated at fixed time $40 \mathrm{~h}$ following progestagen removal, using the same breed fertile bucks (1:5 mating ratio). The total estrous response for the first $12 \mathrm{~h}$, total estrous response within $60 \mathrm{~h}$, time to onset of the induced estrus, duration of the induced estrus and pregnancy rate were $3.0,96.9 \%$, $26.5 \pm 0.7 \mathrm{~h}, 22.6 \pm 0.8 \mathrm{~h}$ and $92.0 \%$, respectively. In terms of the onset of induced estrus there were significant differences between group 1 and groups 3 and 4 and between group 2 and group $3(\mathrm{P}<0.05)$. The protocols used were equally efficient in synchronizing and inducing estrus in non-lactating Anatolian black does during the natural breeding season. Conclude on pregnancy rate. In addition, pregnancy rates were similar results.
\end{abstract}

Keywords: cloprostenol, eCG, estrus synchronization, goat, MAP.

\section{Introduction}

Most breeds of goats show seasonality in reproduction activities, due to season changes, latitude/longitude, the length of the photoperiod and other factors (Amoah et al., 1996; Simões, 2015). During a year, reproductive activity in goats is composed of non-breeding season, transition period and breeding season (Pierson et al., 2001). Thus, various protocols have been developed to control reproduction activities throughout the year including the buck effect, photoperiod treatments and the use of exogenous hormone treatment (Whitley and Jackson, 2004; LopezSebastián et al., 2014). Exogenous hormones such as progesterone or its synthetic analogues, equine chorionic gonadotrophin (eCG) and prostaglandin $\mathrm{F} 2 \alpha$ (PGF2 $\alpha$ ) are generally used in the reproductive season of goats (Dogan et al., 2005), outside the natural breeding season (Corteel et al., 1988; Souza et al., 2011; Pietroski et al., 2013) and in the transition period (Dogan et al., 2004, 2008a, b). Estrous synchronization in goats is achieved by control of the luteal phase of the estrous cycle, either by providing exogenous progesterone or by inducing premature luteolysis (Gordon, 1999). Progestagens are the main hormones used for synchronization and/or induction of estrus in goats (Bretzlaff and Romano, 2001). Intravaginal sponges impregnated with different progestagens, mainly medroxyprogesterone acetate (MAP) and fluorogestone acetate (FGA) are the most appropriate hormonal techniques used for controlled breeding in goats (Wildeus, 2000). Traditionally, progestagen treatment in goats is either longer or similar to the lifespan of a cyclic corpus luteum. The most common treatments for estrous synchronization in goats, regardless of stage of the cycle or follicular status of the ovary at the time of treatment or season, are based on long progestagen (progesterone or a synthetic analogue) exposure (11 or 21 days) associated with an intramuscular (i.m.) injection of eCG alone or eCG with PGF2 $\alpha$ given at the end of the treatment (Corteel et al., 1988; Gordon, 1999). Following treatment, a high rate of does show estrus within a relative short time, but fertility rate is generally low or variable (Dogan et al., 2004, 2008a, b; Pietroski et al., 2013). This phenomenon is related to lower concentration of progesterone/progestogen with abnormalities in follicular development, ovulation, oocyte health, luteal function, alteration in sperm transport and fertility (Corteel et al., 1988; Menchaca et al., 2007). Recently, with the objective to avoid prolonged progesterone exposure, the short term protocol using intravaginal devices during 5-7 days has been proposed for goats (Menchaca et al., 2007; Dogan et al., 2008b; Vilariño et al., 2011; Pietroski et al., 2013). The short term protocol uses progesterone/progestogen, PGF $2 \alpha$ and eCG, and is effective for controlling both luteal activity and follicular dynamics (Menchaca et al., 2007) and also resulting in high pregnancy rates following fixed timed artificial insemination (AI; Vilariño et al., 2011) or after natural mating (Souza et al., 2011). The objective of this study was to evaluate different progestagen treatment duration on estrous synchronization and pregnancy rate in non-lactating Anatolian black goats during the natural breeding season. 


\section{Material and Methods}

The study was carried out at village located in Inegol, Bursa (latitude $40^{\circ} 13^{\circ} \mathrm{E}$, longitude $29^{\circ} 00^{\prime} \mathrm{N}$, altitude $100 \mathrm{~m}$ ) in western Turkey, during October (the natural breeding season) under natural lighting. The ambient temperature, relative humidity and the monthly rainfall during the experiment were $15.2^{\circ} \mathrm{C}, 69 \%$ and $68.8 \mathrm{~kg} / \mathrm{m}^{2}$, respectively. A total of 98 cyclic nonlactating hair Anatolian black does ranging in age from 2 to 4 years $(3.0 \pm 1.1$ years $)$, weighing 35 to $50 \mathrm{~kg}$ $(42.6 \pm 7.8 \mathrm{~kg})$ and with $3.0 \pm 0.1$ body condition (BC) score (evaluated on a scale of 1 to 5; Morand-Fehr et al., 1989) were evaluated. In addition, 20 Anatolian black breeding bucks of proven fertility and 5 teaser bucks were used in the present study. The does were allowed to graze on natural pasture from 07:30 to 11:30 $\mathrm{h}$ and from 13:30 to $17: 30 \mathrm{~h}$ and kept in pen overnight. Water and mineral salt lick were provided ad libitum. In addition, goats received $0.5 \mathrm{~kg}$ commercial concentrate ( $15 \%$ crude protein) doe/day during the entire period of study. The management of the does did not change throughout the entire experimental period.

The experimental does were divided into 4 groups according to the age, body weight and body condition scores. The does were synchronized by inserting $60 \mathrm{mg}$ MAP (Esponjavet, Hipra, Spain) vaginal sponges for 13, 11, 9 and 6 days in groups 1, 2, 3 and 4, respectively. Goats were allocated in three groups of 25 animals and one group of 23 does. In addition, whatever the group, each goat received $0.075 \mathrm{mg}$ of cloprostenol (PGF2 $\alpha$, Dalmzin, Fatro, Italy) and 500 IU eCG (ChronoGest, Intervet, Netherlands) i.m. $24 \mathrm{~h}$ before sponges removal. In group 1, group 2 and group 3 the treatment was initiated 7, 5 and 3 days earlier, respectively, compared to group 4 in order to synchronize sponges removal, PGF2 $\alpha$ and eCG administration. Estrus was monitored every $6 \mathrm{~h}$ from 12 to $60 \mathrm{~h}$ after sponge removal and with the aid of 5 teaser bucks. A doe was diagnosed in estrus when it stood to be mounted by a teaser buck. The onset of estrus was defined as the time between sponge removal and the first accepted mount of the doe and estrous duration as the time between the first and last accepted mount, within the same estrous period. Each doe within the same estrous period was naturally mated in paddock at fixed $40 \mathrm{~h}$ following sponge withdrawal, using 20 Anatolian black fertile bucks (1:5 mating ratio). One mating was performed in each goat. The mating was controlled and observed. All does were tested for pregnancy 60 days following natural mating with the aid of a trans-abdominal ultrasonic scanning apparatus $(5.0-\mathrm{MHz}$ linear probe, Honda, HS-1500, Japan). The fetal heartbeat and the fetal image were used in the diagnosis of pregnancy.

The onset of estrus and duration of induced estrous periods were subjected to analyses of variance (one-way ANOVA) and differences between means were tested for significance with the Fisher's PLSD. Estrous response (12 and within $60 \mathrm{~h}$ ) and pregnancy rates were analyzed using the chi-square test and Fisher's exact test, respectively, the 95\% significance level was noted. SPSS 10.0 software was used for statistical analyses (Instat, 1990-1993. Grophpad instat copyright (c) Grophpad software)

\section{Results}

The results in terms of estrous response for the first $12 \mathrm{~h}$ and within $60 \mathrm{~h}$ after progestagen treatment, time to onset and duration of the induced estrous and pregnancy rates are set out in Table 1. The Fig. 1 illustrates the intervals between sponge removal and the onset of estrus. One doe from group 1, one doe from group 3 and one doe from group 4 did not show any overt signs of estrus during the observation period but these does were mated by bucks. Estrous appearance for the other does occurred between 12 and $60 \mathrm{~h}$ after the end of treatment. Synchronization parameters (estrous response, onset and duration of estrus) and pregnancy rates were not significantly different among the four groups $(\mathrm{P}>0.05)$, except for significant differences in the onset of induced estrus period among group 1 and groups 3 and 4 and between group 2 and group 3 (P < $0.05)$. Thus, data were pooled. The overall estrous response for the first $12 \mathrm{~h}$ period and within $60 \mathrm{~h}$ after progestagen treatment were 3.0 and $96.9 \%$, respectively. The overall mean time to onset and duration of estrus following sponge removal were $26.5 \pm 0.7 \mathrm{~h}$ and $22.6 \pm$ $0.8 \mathrm{~h}$, respectively. The overall mean pregnancy rate at day 60 following natural mating was $92.0 \%$, with 2 of 3 does not showing any estrous response, but diagnosed pregnant at day 60 after natural mating.

Table 1. Estrous response rate, onset and duration of estrus and pregnancy rate in Anatolian black does following four different progestogen treatments using natural mating at a fixed time during breeding season in non lactating goats

\begin{tabular}{|c|c|c|c|c|c|c|c|}
\hline \multirow{3}{*}{$\begin{array}{l}\text { Treatment } \\
\text { group }\end{array}$} & \multirow{3}{*}{$\begin{array}{c}\text { Duration of } \\
\text { progestagen } \\
\text { treatment (days) }\end{array}$} & \multirow[t]{3}{*}{$\mathrm{n}$} & \multicolumn{4}{|c|}{ Estrous } & \multirow{3}{*}{$\begin{array}{c}\text { Pregnancy rate } \\
(\%)\end{array}$} \\
\hline & & & \multicolumn{2}{|c|}{ Response (\%) } & \multirow[t]{2}{*}{ Onset (h) } & \multirow[t]{2}{*}{ Duration (h) } & \\
\hline & & & $12 \mathrm{~h}$ & within $60 \mathrm{~h}$ & & & \\
\hline Group 1 & 13 & 23 & $(20 / 3) 13$ & $(22 / 1) 95.7$ & $23.5 \pm 2.2^{\mathrm{a}}$ & $23.6 \pm 2$ & $(20 / 3) 91$. \\
\hline Group 2 & 11 & 25 & $(25 / 0) 0$ & (25/25) 100 & $25.4 \pm 0.7^{\mathrm{ac}}$ & $23.5 \pm 1.1$ & $(25 / 25) 100$ \\
\hline Group 3 & 9 & 25 & $(25 / 0) 0$ & $(24 / 1) 96$ & $28.8 \pm 1^{\mathrm{b}}$ & $21.0 \pm 1.5$ & $(22 / 3) 88$ \\
\hline Group 4 & 6 & 25 & $(25 / 0) 0$ & $(24 / 1) 96$ & $28.3 \pm 1 .^{1 b c}$ & $22.3 \pm 1.6$ & $(22 / 3) 88$ \\
\hline Total & & 98 & $(95 / 3) 3$ & $(95 / 3) 96.9$ & $26.5 \pm 0.7$ & $22.6 \pm 0.8$ & (89/9) 92 \\
\hline
\end{tabular}

Include information about dose and time of administration of eCG and PGF2 $\alpha$. Each goat received $0.075 \mathrm{mg}$ of cloprostenol (PGF2 $\alpha$ ) and 500 IU eCG i.m. 24 h before sponges removal. ${ }^{\mathrm{a}, \mathrm{b}, \mathrm{c}}$ means in the same column, with different superscripts indicate a significant difference $(\mathrm{P}<0.05)$. 


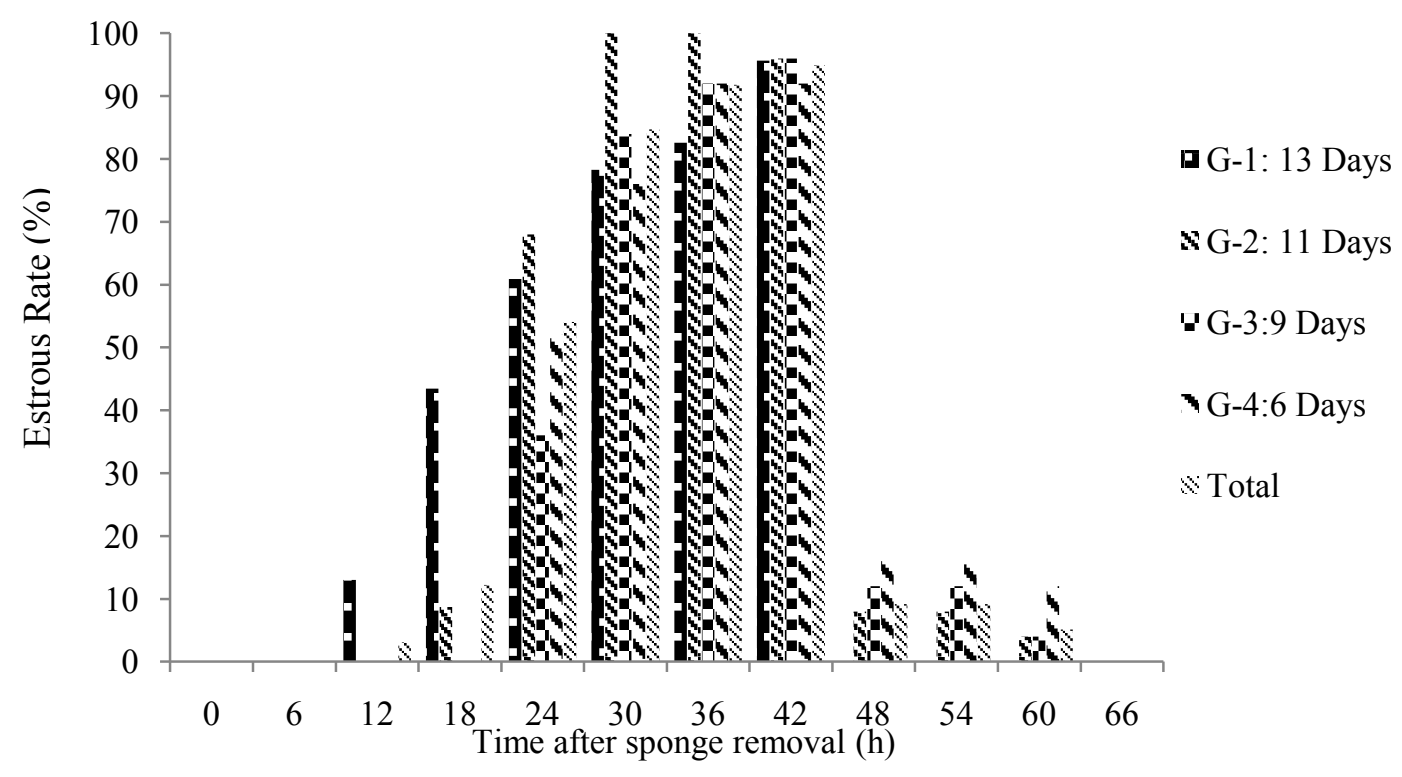

Figure 1. Intervals between sponge removal and onset of estrus in Anatolian black does following four different progestagen treatments using natural mating at fixed time. Complete with the data of treatment used in each group; include title in vertical axis (estrous rate).

\section{Discussion}

The four treatments used in this study, regardless of the duration of progestagen treatment, were found to be efficient for estrous induction and synchronization in non-lactating Anatolian black does during the natural breeding season. There were no significant differences in the rate of estrous response in the first $12 \mathrm{~h}$ period among the four groups. These results are in agreement with those of Freitas et al. (1997) who reported that estrous response for the first $12 \mathrm{~h}$ period of lactating Alpine and Saanen goats was $10 \%$ when either $45 \mathrm{mg}$ FGA sponge, $1.5 \mathrm{mg}$ or $3 \mathrm{mg}$ norgestomet ear implant for 11 days with 400 or 500 IU eCG and $50 \mu \mathrm{g}$ cloprostenol were applied to synchronize estrus but in anestrus goats. However, using $20 \mathrm{mg}$ FGA sponge for 6, 9 and 11 days with 500 IU eCG and $0.075 \mathrm{mg}$ cloprostenol, Dogan et al. (2008b) reported 20, 15 and 55\% estrous response for the first $12 \mathrm{~h}$ period in Turkish Saanen does, respectively, during the transitional period. The variation observed in estrous concentration in the first $12 \mathrm{~h}$ period after progestagen treatment among authors could be due to differences in the rate of absorption and metabolization of each progestagen and/or differences in reproductive seasonality. Considering overall estrous response for the first $12 \mathrm{~h}$ period $(3 \%)$, our result was lower than those of Dogan et al. $(2005,2008 \mathrm{~b})$ and Nogueira et al. (2011), in which different breeds of goats under different environmental conditions were studied.

Within $60 \mathrm{~h}$ after progestagen removal, there were no significant differences among the four groups in terms of estrous response rate. The high estrous response recorded during the $60 \mathrm{~h}$ observation period following the cessation of treatment (overall mean response $\sim 97 \%$ ) was within the range of 90 to $100 \%$ estrous response obtained by Pietroski et al. (2013), after treatments with intravaginal sponges containing MAP applied for 12 or 9 or 6 days plus the administration of eCG and PGF2 $\alpha 24 \mathrm{~h}$ before sponges removal. In the present study, the overall mean estrous response was high compared with the result obtained by Fonseca and Torres (2005) and Fonseca et al. (2005), who reported 83.1 and $89.5 \%$ of animals in estrus after 6-day and 9-day protocols with MAP sponge, respectively, using $200 \mathrm{IU} \mathrm{eCG}$ and $22.2 \mu \mathrm{g} d-$ cloprostenol in goats (include breed). The estrous response in the present study was within the range of 78.6 to $100 \%$ quoted in treatments with intravaginal sponges containing FGA or MAP for 11 days or 14 days plus an i.m. administration of eCG and PGF $2 \alpha 48 \mathrm{~h}$ prior to or at sponges removal by Dogan et al. (2004, 2005, 2008a, b), Amarantidis et al. (2004), Bukar et al. (2012) and Omontese et al. (2013). In the present study, it was possible to reduce the duration of treatment from 13 days to 11 or 9 or 6 days while maintaining hormonal treatment efficiency on estrous induction and pregnancy rate.

Researchers have reported that onset of estrus in goats occurs within 12-120 h following progestagen withdrawal (Dogan et al., 2004, 2005, 2008 a, b; Fonseca et al., 2005; Lertchunhakiat et al., 2012; Omontese et al., 2013). In the present study, estrous concentration was between 12 and $60 \mathrm{~h}$ after sponge withdrawal, with the highest rate of estrus occurring between 36 and $42 \mathrm{~h}$. According to present results, total distribution of estrus was similar to that reported by Fonseca et al. (2005) and Dogan et al. (2008a, b), who found the highest rate of estrous onset to occur between 36 and $42 \mathrm{~h}$ after MAP or FGA sponge withdrawal, but other studies found an earlier occurrence of estrous 
onset (Dogan et al., 2005). In the current study, the mean overall interval to the onset of estrus, following progestagen removal, was $26.5 \pm 0.7 \mathrm{~h}$. This value was similar to Pietroski et al. (2013), who reported a 26.7, 25.2 and $25.2 \mathrm{~h}$ interval to estrus in Saanen goats, after using MAP sponge for 6, 9, and 12 days, respectively. Similarly, Dogan et al. (2005) using the same protocol as in the present study (11 days), reported $20.6 \mathrm{~h}$ interval to onset of estrus in Anatolian black goats during the natural breeding season. Fonseca and Torres (2005), using the same protocol as in the present study (9 days), reported $30 \mathrm{~h}$ and $32 \mathrm{~h}$ interval to the onset of estrus in Alpine and Saanen goats, respectively. In a previous study, Dogan et al. (2004), after using 11-day sponge treatments of MAP or FGA with 750 IU eCG and $125 \mu \mathrm{g}$ cloprostenol, reported an interval of $15.4 \mathrm{~h}$ to the onset of estrus in non-lactating Saanen goats in the transition period. This greater dose of eCG could have induced greater ovarian activity, which could have decreased the interval to onset of estrus (Amarantidis et al., 2004; Omontese et al., 2013). On the other hand, present results were shorter than those of Omontese et al. (2013), who recorded an interval of 44.2 and $29.3 \mathrm{~h}$ to onset of estrus with 14 days FGA sponge alone or FGA sponge with eCG, respectively, in Red Sokoto goats. Similarly, using $45 \mathrm{mg}$ FGA sponges for 14 days with $300 \mathrm{IU}$ eCG and $7.5 \mathrm{mg}$ PGF2 $\alpha$, Bukar et al. (2012) reported a $41.1 \mathrm{~h}$ interval to estrus in cyclic Boer goats. Fonseca et al. (2005), after using eCG plus cloprostenol for 9 or 6 days of MAP sponge treatment, reported an interval of 53.6 and $46.1 \mathrm{~h}$ for the onset of estrus for non-lactating Toggenburg does, respectively. The reason for variation in the interval after hormonal treatment to estrous onset might be due to the effect of breed, dose of eCG, nutrition and/or season, which is known to have an influence on plasma progesterone level (Amarantidis et al., 2004). Include reference for time and dose of eCG/PGF2 $\alpha$ (Dogan et al. 2008a, b).

The mean overall duration of the induced estrous period was $22.6 \pm 0.8 \mathrm{~h}$. According to previous studies in different breeds, it was observed that average estrous duration was in Saanen goats, $32.5 \mathrm{~h}$ (Dogan et al., 2004), Greek, $29.7 \mathrm{~h}$ (Amarantidis et al., 2004), Toggenburg, 27.2 and $30.0 \mathrm{~h}$ (Fonseca et al., 2005), Anatolian black, 29.7 h (Dogan et al., 2005), Turkish Saanen, 29.4 h (Dogan et al., 2008b), Turkish Saanen, 29.3 h (Dogan et al., 2008a), Boer, 36.0 h (Bukar et al., 2012) and in Red Sokoto, $30.8 \mathrm{~h}$ (Omontese et al., 2013). The protocols used in the present study did not affect the duration of the induced estrous period, but it was shorter compared with results obtained in other studies. However, Fonseca and Torres (2005) reported a short estrous duration of 14.7 and $17.3 \mathrm{~h}$ in Alpine and Saanen goats, respectively. In previous studies, it was reported that mating decreased the duration of estrus (Romano, 1993). One service reduced the duration of estrus by $45 \%$; but estrous duration was not affected whether the goat was served once, twice or three times (Romano, 1994b; Romano et al., 2016). The author suggested that penis intromission stimulates mechanisms involved in estrous shortening (Romano, 1994a). Thus, it appears that the effect of copulation with fertile buck at $40 \mathrm{~h}$ after the onset of estrus could have been responsible for the shortening in the duration of the estrous period.

None of the treatment protocols showed any significant advantage on conception rate. Also, using FGA sponge for 6,9 and 11 days with eCG and cloprostenol, Dogan et al. (2008b) did not report any difference in pregnancy rates in Turkish Saanen goats, using fixed-time AI with frozen-thawed semen. Likewise, using the same protocols as in the present study (6 and 9 days), Pietroski et al. (2013) reported that pregnancy rates were not different after AI or natural mating in Saanen goats. The overall post-treatment conception rate obtained with natural mating in this study was $92 \%$ and similar to results obtained by Amarantidis et al. (2004), who recorded an average pregnancy rate of $86.4 \%$ in FGA sponge treated goats, after natural mating with known fertility bucks. Results observed in the present study were higher than values within the range of 51.2 to $75.3 \%$ reported for goats synchronized with intravaginal progestagen sponges or progesterone devices during the breeding (Dogan et al.,2005), non-breeding season (Vilariño et al., 2011) and transition period (Dogan et al., 2004) after fixedtime AI with fresh diluted semen. The results in pregnancy rate may differ among authors considering breed, season, natural mating, AI using fresh, diluted or frozen-thawed semen, synchronization protocols, lifespan of spermatozoa and oocyte and overall management conditions.

Two of three does did not show any overt signs of estrus, but were diagnosed pregnant at day 60 after natural mating. Such a finding is in agreement with a previous report in Anatolian black goats (Dogan et al., 2005), synchronized with MAP or FGA sponges. Allison and Robinson (1970) suggested that these silent ovulations may be related to inadequate endogenous progesterone levels. Besides, absence of estrus and ovulation may be due to insufficient gonadotrophic hormone released by the pituitary, to a poor ovary response to exogenous eCG or variation in responsiveness of animals to eCG (Rubianes and Menchaca, 2003).

In conclusion, protocols used in the present study were equally efficient in synchronizing and inducing estrus in non-lactating Anatolian black does during the natural breeding season. Conclude on pregnancy rate. In addition, pregnancy rates did not differ among the groups. According to results of the present study, reduction in the duration of progestagen treatment can be used without affecting reproductive efficiency.

\section{Conflict of interest}

There is no conflict of interest to declare.

\section{References}

Allison AJ, Robinson TJ. 1970. The effect of does level of intravaginal progestagen on sperm transport, fertilization and lambing in the cyclic Merino ewe. $J$ 
Reprod Fertil, 22:515-531.

Amarantidis I, Karagiannidis A, Saratsis Ph, Brikas P. 2004. Efficiency of methods used for estrous synchronization in indigenous Greek goats. Small Rumin Res, 52:247-252.

Amoah EA, Gelaye S, Guthrie P, Rexroad CE. 1996 Breeding season and aspects of reproduction of female goats. J Anim Sci, 74:723-728.

Bretzlaff KN, Romano JE. 2001. Advanced reproductive techniques in goats. Vet Clin $N$ Am Food Anim Pract, 17:421-434.

Bukar MM, Yusoff R, Haron AW, Dhaliwal GK, Khan MAG, Omar MA. 2012. Estrus response and follicular development in Boer does synchronized with flugestone acetate and PGF $2 \alpha$ or their combination with eCG or FSH. Trop Anim Health Prod, 44:1505-1511.

Corteel JM, Leboeuf B, Baril G. 1988. Artificial breeding of goats and kids induced to ovulate with hormones outside the breeding season. Small Rumin Res, 1:19-35.

Dogan I, Nur Z, Gunay U, Soylu MK, Sonmez C. 2004. Comparison of fluorgestone and medroxyprogesterone intravaginal sponges for oestrus synchronization in Saanen does during the transition period. S Afr J Anim Sci, 34:18-22.

Dogan I, Nur Z, Gunay U, Sagirkaya H, Soylu MK, Sonmez C. 2005. Estrous synchronization during the natural breeding season in Anatolian black does. Vet Med Czech, 50:33-38.

Dogan I, Konyali A, Tolu C, Yurdabak S. 2088a. Different estrous induction protocols during the transition period in lactating Turkish Saanen does following AI. Acta Vet (Beograd), 58: 259-266.

Dogan I, Konyali A, Gunay U, Yurdabak S. 2008b. Comparison of the effect of cronolone sponges and PMSG or cloprostenol on estrous induction in Turkish Saanen goats. Pol J Vet Sci, 11:29-34.

Fonseca JF, Bruschi JH, Santos ICC, Viana JHM, Magalhães ACM. 2005. Induction of estrus in nonlactating dairy goats with different estrous synchrony protocols. Anim Reprod Sci, 85:117-124.

Fonseca JF, Torres CAA. 2005. Administration of hCG 5 days after breeding and reproductive performance in nulliparous dairy goats. Reprod Domest Anim, 40:495-499.

Freitas VJF, Baril G, Saumande J. 1997. Estrus synchronization in dairy goats:use of fluorogestone acetate vaginal sponges or norgestomet ear implants. Anim Reprod Sci, 46:237-244.

Gordon I (Ed.). 1999. Controlled Reproduction in Sheep \& Goats. Wallingford, UK: CABI International. $272 \mathrm{pp}$.

Lertchunhakiat K, Navanukraw $\mathbf{C}$, Thammasiri J, Jaikan W, Swannakorn A, Moonmanee T, Redmer DA. 2012. Evaluation of protocols based on synthetic progesterone and gonadotropin on estrus and ovulatory response in Thai-Native goats. $J$ Anim Vet Adv, 11:3385-3389.

Lopez-Sebastián A, Coloma MA, Toledano A,
Santiago-Moreno J. 2014. Hormone-free protocols for the control of reproduction and artificial insemination in goats. Reprod Domest Anim, 49(suppl. 4):22-29.

Menchaca A, Miller V, Salveraglio V, Rubianes E. 2007. Endocrine, luteal and follicular responses after the use of the short-term protocol to synchronize ovulation in goats. Anim Reprod Sci, 102:76-87.

Morand-Fehr P, Hervieu J, Santucci P. 1989. Notation de I'etat corporel: a vos stylos. La Chevre, 175:39-42.

Nogueira DM, Lopes Júnior ES, de Peixoto RM, Christilis M, Martins SR, do Monte APO. 2011. Using the same CIDR up to three times for estrus synchronization and artificial insemination in dairy goats. Acta Sci Anim Sci, 33:321-325.

Omontese BO, Rekwot PI, Makun HJ, Ate IU, Rwuaan JS, Kawu MU. 2013. Oestrus induction using fluorogestone acetate sponges and equine chorionic gonadotrophin in Red Sokoto goats. S Afr J Anim Sci, 43:68-73.

Pierson JT, Baldassarre H, Keefer CL, Downey BR. 2001. Seasonal variation in preovulatory events associated with synchronization of estrus in dwarf goats. Theriogenology, 56:759-769.

Pietroski ACCA, Brandão FZ, de Souza JMG, da Fonseca JF. 2013. Short, medium or long-term hormonal treatments for induction of synchronized estrus and ovulation in Saanen goats during the nonbreeding season. Rev Bras Zootec, 42:168-173

Romano JE. 1993. Effect of service on estrus duration in dairy goats. Theriogenology, 40:77-84.

Romano JE. 1994a. Effects of different stimuli of sevice on eatrus duration in dairy goats. Theriogenology, 42:875-879.

Romano JE. 1994b. Effects of service number on estrus duration in dairy goats. Theriogenology, 41:1273-1277.

Romano JE, Alkar A, Amstalden M. 2016. Effect of copulation on estrus duration and ovulation time in goats. Theriogenology, 85:330-334.

Rubianes E, Menchaca A. 2003. The pattern and manipulation of ovarian follicular growth in goats. Anim Reprod Sci, 78:271-287.

Simões J. 2015. Recent advances on synchronization of ovulation in goats, out of season, for a more sustainable production. Asian Pac J Reprod, 4:157-165.

Souza JMG, Torres CAA, Maia ALRS, Brandão FZ, Bruschi JH, Viana JHM, Oba E, Fonseca JF. 2011. Autoclaved, previously used intravaginal progesterone devices induces estrus and ovulation in anestrous Toggenburg goats. Anim Reprod Sci, 129:50-55.

Vilariño M, Rubianes E, Menchaca A. 2011. Re-use of intravaginal progesterone devices associated with the Short-term Protocol for timed artificial insemination in goats. Theriogenology, 75:1195-1200.

Whitley NC, Jackson DJ. 2004. An update on estrus synchronization in goats: a minor species. J Anim Sci, 82:E270-E276.

Wildeus S. 2000. Current concepts in synchronization of estrus: sheep and goats. J Anim Sci, 77:1-14. 